\title{
Responsiveness of Urinary Cyclic AMP and Phosphate to Parathyroid Extract in Patients with Parathyroid Disorders
}

\author{
Mitsuyasu Aida, Yotaro Hurukawa, Kiyoshi Miura, ${ }^{*}$ \\ Akio Minara, Katsuhiko Kato, Takehiro Tano, \\ Motoko Ojima, Kunihiko Haniw, Osamu Murakami, \\ Shyi-Chang Lee and Kaoru Yoshinaga \\ Department of Internal Medicine, Tohoku University School of \\ Medicine, Sendai and Department of the Third Internal \\ Medicine,* Gifu University School of Medicine, Gifu
}

Ama, M., Hurukawa, Y., Mrura, K., Mirara, A., Kato, K., Tano, T., Ojmia, M., Hantw, K., Murakamt, O., Lee, S.-C. and Yoshmaga, K. Responsiveness of Urinary Cyclic AMP and Phosphate to Parathyroid Extract in Patients with Parathyroid Disorders. Tohoku J. exp. Med., 1975, 115 (4), 319-325

Responsiveness of urinary cyclic AMP and phosphate to 200 units of parathyroid extract was evaluated in 5 normal subjects, 2 patients with idiopathic hypoparathyroidism, 4 patients with pseudohypoparathyroidism and 3 patients with primary hyperparathyroidism. Among them, 3 patients with pseudohypoparathyroidism were examined prior to and during therapy with vitamin D. Two patients with primary hyperparathyroidism were examined before and after removal of adenomas. In control subjects, percent increase in cyclic AMP after parathyroid extract administration was $7265 \pm 3312 \%$, and in phosphate $290 \pm$ $72 \%$. It was found that in idiopathic hypoparathyroidism the response of eyclic AMP was in the normal range, though that of phosphate was higher than normal. In pseudohypoparathyroidism, as distinguished from what Drezner et al. called pseudohypoparathyroidism type II, the response of cyclic AMP was uniformly low, while that of phosphate was variable. Similar results were obtained during treatment with vitamin $D$. In primary hyperparathyroidism, the responses of both cyclic AMP and phosphate were lower than normal. After removal of adenomas, the response of phosphate became normal, but the response of cyclic AMP rose to a subnormal level in one patient, and remained low in the other. For the diagnosis of pseudohypoparathyroidism, the response in cyclic AMP was considered to be a more reliable index than that in phosphate whether the patient was being treated with vitamin D or not._—_ urinary cyclic AMP and phosphate; parathyroid extract; idiopathic hypoparathyroidism; pseudohypoparathyroidism; primary hyperparathyroidism

The Ellsworth-Howard test (1934), which consists of comparison of urinary phosphate before and after intravenous injection of parathyroid extract (PTE), is most frequently used for differentiating the patients with idiopathic hypoparathyroidism from those with pseudohypoparathyroidism. The phosphaturic response, however, sometimes gives an equivocal result; therefore, there are several slightly

Received for publication, December 19, 1974. 
different criteria based on the phosphaturic response (Bronsky et al. 1958: Bartter 1966) for the differentiation of parathyroid gland disorders. Chase et al. (1969) demonstrated that there was little or no increase in the urinary excretion of cyclic AMP in response to the administration of PTE to individuals with pseudohypoparathyroidism, while a significant increase in cyclic AMP excretion resulted from similar treatment in patients with idiopathic hypoparathyroidism. As a result of their work, measurement of cyclic AMP has been recognized as a particularly useful diagnostic means for pseudohypoparathyroidism. In the present paper, the responses of both urinary cyclic AMP and phosphate to PTE administration were compared in the individuals with various parathyroid gland disorders, and their diagnostic values were discussed.

\section{Materials and Methods}

Responsiveness of urinary cyclic AMP and phosphate to PTE were studied in 5 control subjects, 4 patients with pseudohypoparathyroidism, 2 patients with idiopathic hypoparathyroidism, and 3 patients with primary hyperparathyoridism. The main clinical and laboratory data on these individuals are summarized in Table 1. The ages of the control subjects ranged from 14 to 56 years. Among the 4 patients with pseudohypoparathyroidism, 3 were examined for their response to PTE before and during treatment with $100,000-300,000$ units of vitamin $D_{2}$. Two of the 3 patients with primary hyperparathyroidism were examined for their responsiveness to PTE before and after removal of adenomas. Shown in Table 2 are the serum calcium and serum phosphorus values in the

TABLE 1. Clinical and laboratory

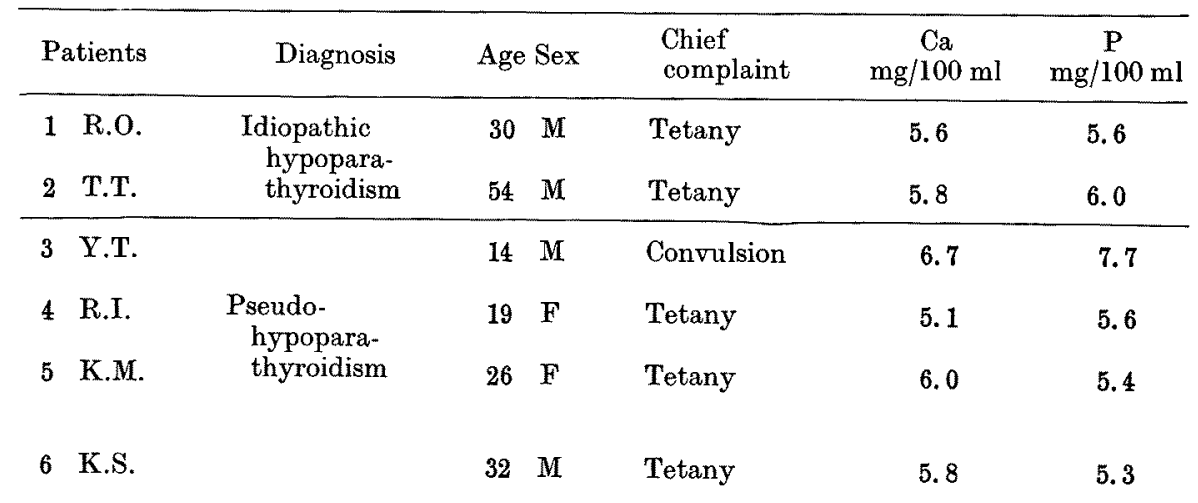

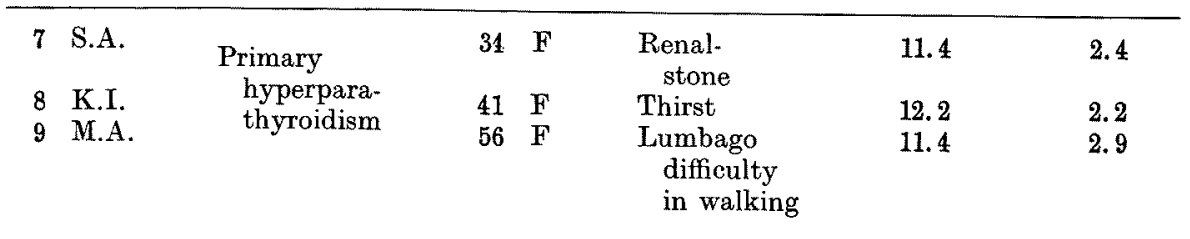


patients with pseudohypoparathyroidism and idiopathic hypoparathyroidism before and during treatment with large amounts of vitamin $D$, and in the patients with primary hyperparathyroidism before and after the operation. For 3 days prior to PTE administra. tion, all the subjects were orally given $100 \mathrm{ml}$ of $10 \%$ aluminum hydroxide a day. On the 4th day at 4:00 p.m., they received intravenously 200 USP units of PTE. Beginning at 1:00 p.m., urine specimens were collected each hour for a period of $6 \mathrm{hr}$. To facilitate prompt collection of sufficient urine, $300 \mathrm{ml}$ of water were initially given, followed by another $200 \mathrm{ml}$ of water after each urination. Throughout the study, the subjects were prohibited to drink milk. Aliquots of urine were stored at $-20^{\circ} \mathrm{C}$ until the amounts of cyclic AMP and creatinine were determined. Urinary cyclic AMP was measured with the radioimmunoassay method developed by Steiner et al. (1972). The antibody and radioactive antigen were obtained from Schwarz/Mann, New York. Measurement was done in duplicate. The intraassay coefficient of variation was $12.5 \%$. Urine samples were diluted to a ratio of $1: 50$ with $0.05 \mathrm{M}$ sodium acetate buffer $\mathrm{pH} 6.2$, and $10-20 \mu \mathrm{l}$ of the sample so diluted was used for assay. Phosphorus was measured with the Fiske and Subbarow method.

\section{RESULTS}

Table 3 shows the urinary cyclic AMP and phosphate responses to intravenous administration of 200 units of PTE in the patients with various parathyroid diseases and in control subjects. Results, shown as percentile increase in the table, were expressed as the difference between the mean control values and the peak responses after PTE injection (Bronsky et al. 1958). In control subjects, percentile increase in urinary cyclic AMP after PTE administration was $7265 \pm$

data of the patients

\begin{tabular}{|c|c|c|c|c|c|}
\hline $\begin{array}{l}\text { Alkali } \\
\text { phos. units }\end{array}$ & $\%$ TRP & $\begin{array}{l}\text { Cor. } \\
\mathrm{ml} / \mathrm{min}\end{array}$ & $\begin{array}{c}\mathrm{BUN} \\
\mathrm{mg} / 100 \mathrm{ml}\end{array}$ & Röntgenogram & \\
\hline 6.2 & 99 & 69 & 10 & Normal & Physical \\
\hline $4.8^{*}$ & 93 & 83 & 12 & Normal & signs \\
\hline 20.3 & 96 & 104 & 18 & $\begin{array}{l}\text { Subperiosteal } \\
\text { resorption }\end{array}$ & $\begin{array}{l}\text { Short stature } \\
\text { round face }\end{array}$ \\
\hline 6.5 & 95 & 70 & 11 & $\begin{array}{l}\text { Intrapulpal } \\
\text { calcification }\end{array}$ & Cataract \\
\hline 6.8 & 95 & 85 & 21 & Normal & $\begin{array}{l}\text { Short stature } \\
\text { brachydactyly } \\
\text { round face }\end{array}$ \\
\hline $6.9^{*}$ & 95 & 100 & 15 & $\begin{array}{l}\text { Increased } \\
\quad \text { bone density }\end{array}$ & $\begin{array}{l}\text { Short stature } \\
\text { brachydactyly } \\
\text { round face } \\
\text { subcutaneous } \\
\text { caleification }\end{array}$ \\
\hline 8.0 & 80 & 85 & 12 & Normal & \\
\hline $\begin{array}{r}8.2 \\
29.5\end{array}$ & $\begin{array}{l}68 \\
70\end{array}$ & $\begin{array}{l}87 \\
69\end{array}$ & $\begin{array}{l}10 \\
20\end{array}$ & $\begin{array}{l}\text { Normal } \\
\text { Subperiosteal } \\
\text { resorption } \\
\text { bone cyst } \\
\text { osteosclerosis }\end{array}$ & \\
\hline
\end{tabular}

marks are in Bodansky units. 
TABLE 2. Serum calcium and phosphorus values when Ellsworth-Howard tests were done

\begin{tabular}{|c|c|c|c|c|c|c|}
\hline \multirow{2}{*}{\multicolumn{2}{|c|}{ Patients }} & \multirow{2}{*}{ Diagnosis } & \multicolumn{2}{|c|}{ Before treatment* } & \multicolumn{2}{|c|}{ During treatment* } \\
\hline & & & $\mathrm{Ca} \mathrm{mg} / 100 \mathrm{ml}$ & $P \mathrm{mg} / 100 \mathrm{ml}$ & $\mathrm{Ca} \mathrm{mg/100} \mathrm{ml}$ & $\mathrm{Pmg} / 100 \mathrm{ml}$ \\
\hline 1 & R.O. & \multirow{2}{*}{$\begin{array}{l}\text { Idiopathic } \\
\text { hypopara- } \\
\text { thyroidism }\end{array}$} & 5.6 & 5.6 & 8.8 & 4.6 \\
\hline 2 & T.T. & & 5.8 & 6.0 & 9.6 & 3.8 \\
\hline 3 & Y.T. & \multirow{4}{*}{$\begin{array}{l}\text { Pseudo- } \\
\text { hypopara- } \\
\text { thyroidism }\end{array}$} & 6.7 & 7.7 & 8.3 & 4.4 \\
\hline 4 & R.I. & & 5.1 & 5.6 & 9.6 & 4.1 \\
\hline 5 & K.M. & & 6.0 & 5.4 & 9.1 & 4.2 \\
\hline 6 & K.S. & & 5.8 & 5.3 & 7.8 & 3.3 \\
\hline 7 & S.A. & \multirow{3}{*}{$\begin{array}{l}\text { Primary } \\
\text { hyperpara- } \\
\text { thyroidism }\end{array}$} & 11.4 & 2.4 & \multirow[t]{2}{*}{8.6} & \multirow[t]{2}{*}{3.4} \\
\hline 8 & K.I. & & 12.2 & 2.2 & & \\
\hline 9 & M.A. & & 11.4 & 2.9 & 7.8 & 4.4 \\
\hline
\end{tabular}

* In patients with idiopathic hypoparathyroidism and pseudohypoparathyroidism, treatment with vitamin $\mathrm{D}$; in patients with primary hyperparathyroidism, removal of adenomas.

$3312 \%$ and in urinary phosphate $290 \pm 72 \%$. In the patients with idiopathic hypoparathyroidism, percentile increase in urinary cyclic AMP was as high as in the control subjects, but percentile increase in urinary phosphate was found to be higher than that of the control subjects. Before treatment, the patients with pseudohypoparathyroidism showed phosphaturic response either lower than or identical with that of the control subjects. In contrast to the inconsistency in the phosphaturic response, the response in cyclic AMP was found to be markedly suppressed in the diseased patients when compared to the controls. During treatment with vitamin $\mathrm{D}$, they again showed a low or negligible response in

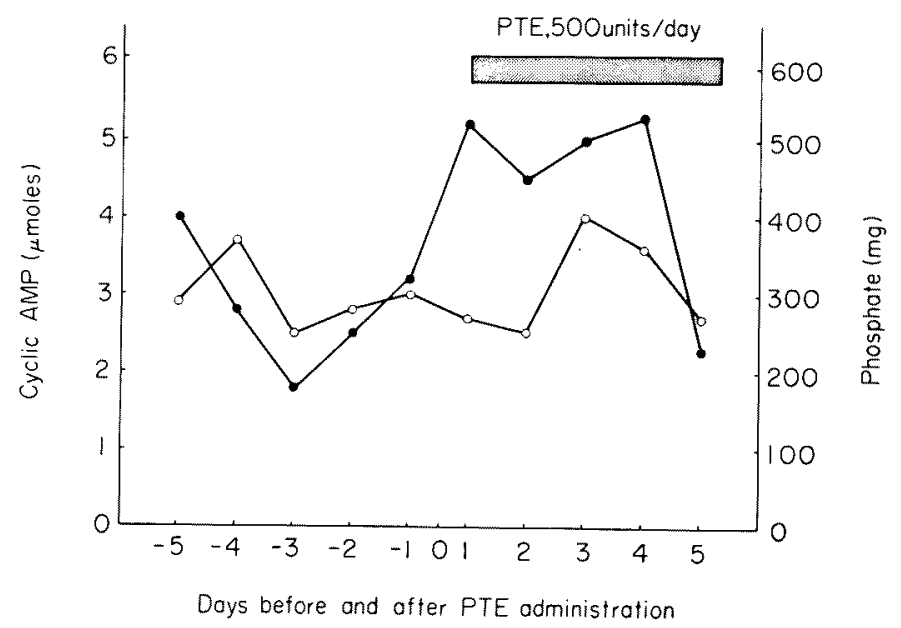

Fig. 1. Daily urinary excretion of cyclic AMP and phosphate before and after administration of 500 units of PTE per day to a patient (Case 4) with pseudohypoparathyroidism. o, cyclic AIIP; •, phosphate. 
TABLE 3. Responses of urinary cyclic AMP and phosphate in the Ellsworth-Howard test

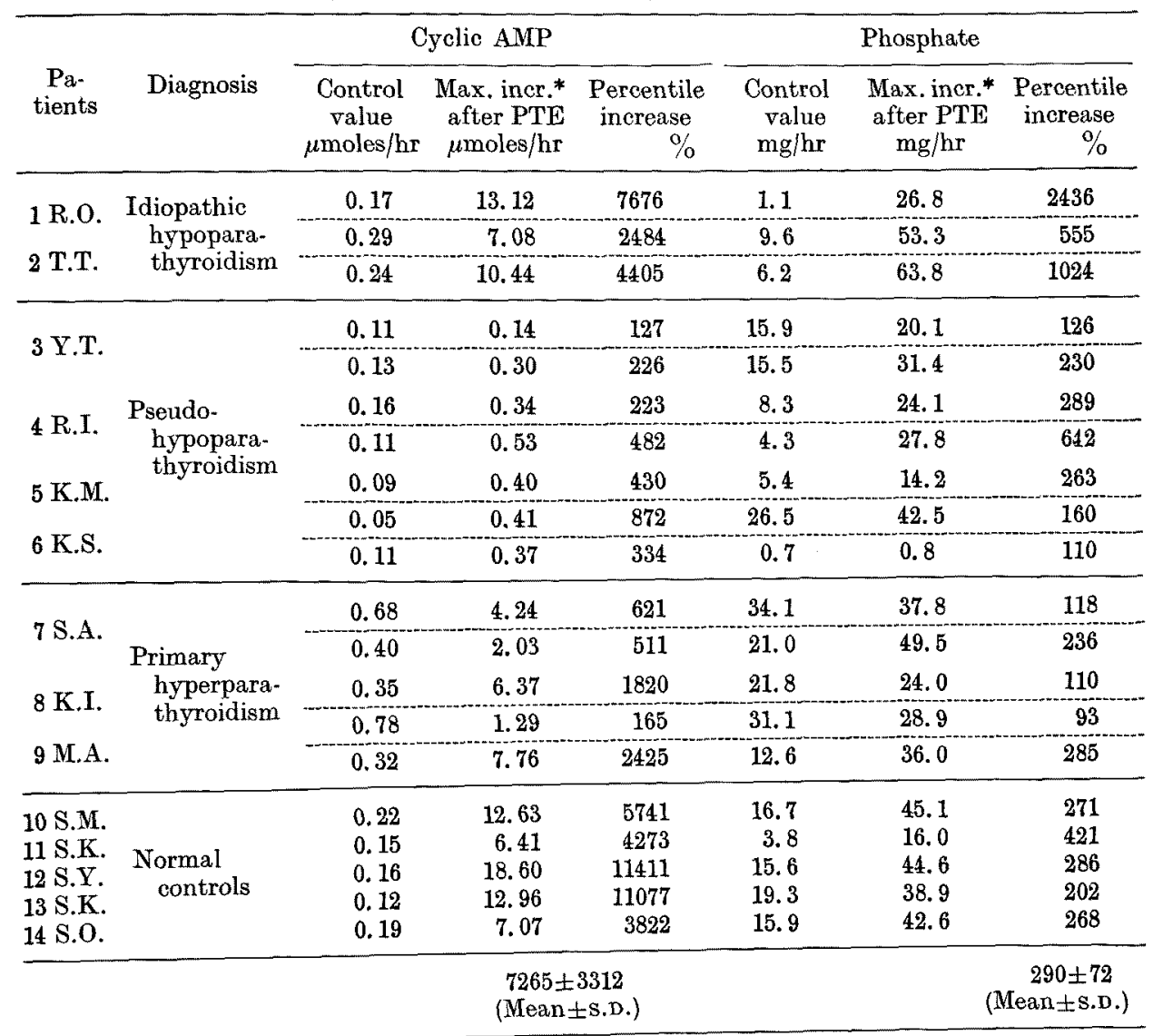

... Numbers above the dotted lines indicate the values before treatment and those below the lines show the values during or after treatment.

* Maximum increase.

cyclic AMP, although the response in urinary phosphate was variable. For the patient (Case 4) in whom phosphaturic response to PTE deviated from expectations both before and during therapy with vitamin $\mathrm{D}$, injection of 500 units of PTE per day was continued for 5 days. Fig. 1 shows daily urinary excretion rates of cyclic AMP and phosphate. In this patient, it was observed that an increment in phosphate occurred without any corresponding increment in cyclic AMP. The patients with primary hyperparathyroidism showed as low a response in urinary cyclic AMP as the patients with pseudohypoparathyroidism, and a uniformly lower response in phosphate than the controls. When they were examined after their adenomas had been removed, cyclic AMP response to PTE rose to a subnormal level in one case, but remained negligible in the other, though in both cases phosphaturic response became normal. 


\section{Discussion}

There are several standards that can be used to evaluate the results of the Ellsworth-Howard test with respect to responsiveness in urinary phosphate. Bronsky et al. (1958) accepted an hourly phosphate increment of $40 \mathrm{mg}$, or a percentile increase exceeding $250 \%$, as indicative of a good response. Bartter (1966) found that in normal subjects there may be an increase in phosphate from two to four times the control values, but in patients with pseudohypoparathyroidism he found either no change, or a small increase of not more than twice the control values. Even between these two standards there are subtle differences. Actually, the phosphaturic responses in our two patients with pseudohypoparathyroidism (Cases 4 and 5) were within the normal range when compared with the above standards and our control subjects. It has been shown that such inconsistencies in the responsiveness of urinary phosphate to PTE sometimes occurred in the patients with pseudohypoparathyroidism. In contrast to this inconsistency, our observation of a constantly negligible response in cyclic AMP in the patients with pseudohypoparathyroidism confirmed that of Chase et al. (1969). In the present study, the hourly inerement in cyclic AMP after 200 units of PTE was at best a 5 -fold rise over the preinjection control values in our patients with pseudohypoparathyroidism, while in the control subjects, the increment was 70 times the preinjection values. Therefore, for diagnostic purpose, the measurement of urinary cyclic AMP seems to be more reliable than that of urinary phosphate. It is interesting to note that the patients with primary hyperparathyroidism showed as low a response in cyclic AMP and phosphate as the patients with pseudohypoparathyroidism. Although these two conditions are quite different clinically, recent investigations have revealed that secretion of the parathyroid hormone was increased in both states (Arnaud et al. 1971: Lee et al. 1968). Lack of response to exogenous PTE in primary hyperparathyroidism may be caused by the saturation of renal target cells with an excess of endogenous parathyroid hormone. We are not certain, however, that this is a full explanation, because one of our cases (Case 7) retained low response in cyclic AMP even after the removal of parathyroidadenoma and the restoration of normal serum calcium and serum phosphorus levels. Lack of response to PTE in pseudohypoparathyroidism may be due to a defective parathyroid hormone-adenyl cyclase system in renal target cells (Chase et al. 1969). Recently Frame et al. (1972) reported that the parathyroid hormone-adenyl cyclase system in the skeleton and kidneys might be vitamin D dependent in certain instances. Their report was based on their observation that a patient with pseudohypoparathyroidism showed normal response to PTE both in serum calcium and in urinary phosphate when amounts of serum calcium and phosphorus reached normal levels during vitamin D treatment. Suh et al. (1970) have also documented a similar case. These two groups of investigators have not evaluated, however, the response of cyclic AMP to PTE in their two patients. All of our 4 patients of pseudohypoparathyroidism showed little or no response in cyclic AMP following therapy with large doses of vitamin D. It might be note- 
worthy that one patient, who had an exaggerated phosphaturic response to PTE during treatment, showed no increase in daily cyclic AMP excretion, even though an increase in phosphate excretion occurred after administration of 500 units of PTE a day for 5 successive days. Very recently, Rodriguez et al. (1974) reported a patient with pseudohypoparathyroidism in whom the rise of urinary phosphate following infusion of PTE was very slight, despite the fact that the increase in urinary cyclic AMP was very similar to that observed in normal subjects. They suggested that their case fits into the category, proposed by Drezner et al. (1973), that can be called pseudohypoparathyroidism type II.

All of our cases with pseudohypoparathyroidism differ from those cases of Rodriguez et al. (1974) and Drenzer et al. (1973), because they show no response to PTE in urinary cyclic AMP. Although further study is required for a full understanding of the relation of urinary cyclic AMP responses to phosphate responses in the patients with pseudohypoparathyroidism, evaluation of the response of urinary cyclic AMP to PTE can be considered useful for diagnosing this disease, even during vitamin $\mathrm{D}$ treatment.

\section{References}

1) Arnaud, C.D., Tsao, H.S. \& Littledike, T. (1971) Radioimmunoassay of human parathyroid hormone in serum. $J$. clin. Invest., 50, 21-34.

2) Bartter, F.C. (1966) Pseudohypoparathyroidism and pseudo-pseudohypoparathyroidism. In: The Metabolic Basis of Inherited Disease. 2nd ed., edited by Stanbury, Wyngaaden \& Friedrickson, McGraw-Hill Book Co., New York, pp. 1024-1029.

3) Bronsky, D., Kushner, D.S., Dubin, A. \& Snapper, I. (1958) Idiopathic hypoparathyroidism and pseudohypoparathyroidism: Case reports and review of the literature. Medicine, 37, 317-352.

4) Chase, L.R., Melson, G.L. \& Aurbach, G.D. (1969) Pseudohypoparathyroidism: Defective excretion of $3^{\prime}, 5^{\prime}$-AMP in response to parathyroid hormone. $J$. clin. Invest., 48, 1832-1844.

5) Drezner, M., Neelon, F.A. \& Lebovitz, H.E. (1973) Pseudohypoparathyroidism type II: A possible defect in the reception of the cyclic AMP signal. Engl. J. Med., 289, 1056-1060.

6) Ellsworth, R. \& Howard, J.E. (1934) Studies on the physiology of the parathyroid glands; VI. Some responses of normal human kidneys and blood to intravenous parathyroid extract. Bull. Johns Hopkins Hosp., 55, 296-308.

7) Frame, B., Hanson, C.A., Frost, H.M., Block, M. \& Arnstein, A.R. (1972) Renal resistance to parathyroid hormone with osteitis fibrosa, "Pseudohypoparathyroidism." Amer. J. Med., 52, 311-321.

8) Lee, J.B., Tashjian, A.H., Jr., Streeto, J.M. \& Frantz, A.G. (1968) Familial pseudohypoparathyroidism. Role of parathyroid hormone and thyrocalcitonin. New Engl. J. Med., 279, 1179-1184.

9) Rodriguez, H.J., Villarreal, H., Jr., Klahr, S. \& Slatopolsky, E. (1974) Pseudohypoparathyroidism type II: Restoration of normal renal responsiveness to parathyroid hormone by calcium administration. J. clin. Endocr., 39, 693-701.

10) Steiner, A.L., Parker, C.W. \& Kipnis, D.M. (1972) Radioimmunoassay for cyclic nucleotides. $J$. biol. Chem., 247, 1106-1113.

11) Suh, S.M., Fraser, D. \& Kooh, S.W. (1970) Pseudohypoparathyroidism: Responsiveness to parathyroid extract induced by vitamin D therapy. J. clin. Endocr., 30, 609-614. 